\title{
Non-keratinocytes of Egyptian Camel (Camelus dromedarius)
}

\section{Doaa, M. Zaghloul and Amira, E.Derbalah}

Department of Histology and Cytology. Faculty of Veterinary Medicine. Alexandria University. Egypt. Author's address: dodomz@hotmail.com

\section{Abstract}

The skin of five male Egyptian camels (Camelus dromedarius) between 10 and15 years old and five male camels between 3 and5 years old were collected and prepared for transmission electron microscopy to study the non- keratinocytes. The melanocytes of camel skin were more numerous in adult camels than in young ones, with a higher number of melanin granules in adults. Merkel cells of camel skin had lobulated nuclei mainly in adult camels, which had also a higher number of dense cored granules than the young ones. But intranuclear rodlets were observed only in young camel skin. The Langerhans cells of adult camel skin were greater in number than in young ones. Round nuclei of Merkel cells were seen only in adult skin. Langerhans cell granules were detected but without a clear racquet shape: rod shapes only could be detected in cross, oblique and longitudinal sections and they were surrounded by a trilaminar membrane. The Langerhans cell granules were few in number inside each cell. All these findings might suggest that the skin is well adapted to protect the animal against harmful effect of the ultraviolet rays of the Egyptian desert environment. This effect mainly increased with age.

\section{Key words}

Non-keratinocytes, Melanocytes, Merkel cell, Langerhans cell, camel, skin.

\section{Introduction}

In prior years the skin of camels has been examined because of the importance of the integument in body temperature regulation in an animal adapted for desert life (Lee and Schmidt-Nielsen, 1962; Ghobrial, 1970).It represents a key site for the regulation of water balance and thermoregulation in desert-adapted mammals (Pfeiffer et al.,2006). At the histological level, the epidermis can be considered relatively thin in the camel (Lee and SchmidtNielsen, 1962). 
Melanocytes are derivatives of neural crest ectoderm located in the basal layer of epidermis. They have spherical nuclei, ribosomes and endoplasmic reticulum (Frappier and Eurell 2006). Melanocytes lack desmosomes and tonofilaments but they possess long branching processes that extend between keratinocytes (Nanci and Tencate, 2008). Melaninis synthesized within melanocytes as small structures called melanosomes. In normal skin the ultrastructure of melanosomesis usually related to the type of melanin they produce (Hearing et al., 1973 \& Jimbow et al., 1979).

The Merkel cell, first described by Merkel in 1875, is a receptor-like cell widely distributed in the epidermis, in the oral epithelium and in the dermal sensory corpuscles of various vertebrates (Munger, 1975\& 1977). The Merkel cell is an epidermal cell with neuro-endocrine properties. It is currently considered to be of epithelial origin (Moll \& Franke, 1984). Winkelmann (1977) found that the Merkel cell is a neural crest migrant to the skin, and it possesses a characteristic intranuclearrodlet, cytoplasmic membrane bound granules, and spiky projections; it is usually associated with nerve terminations. Numerous spiny processes extending from the Merkel cell are intercalated with adjacent keratinocytes, which may detect and amplify movement of adjacent cells. These spiny processes contain a rigid core of parallel microfilaments interrelated with cytoplasmic filament bundles located be- neath the cell membrane (Garant et al., 1979). The synaptic contacts of Merkel cell with nerve endings and accumulation of the specific cored granules in the cytoplasm seem to indicate that the cell releases some neurotransmitter (Tachibana and Nawa, 1980), Straile et al. (1975), described the intranuclear rodlet of the Merkel cell as similar to that of other neuronal cells. Merkel cells are sometimes considered as touch receptors and they have been identified as isolated cells in the dermis without obvious neural connections (Troy and Callender, 1994). Merkel nerve endings are mechanoreceptors in the mammalian skin. They consist of large, pale cells with lobulated nuclei forming synapse-like contacts with enlarged terminal endings of myelinated nerve fibers. Cytoskeletal filaments consisting of cytokeratins and osmiophilic granules containing a variety of neuropeptides are found in Merkel cells (Halata et al., 2003).

Langerhans cells occupy only the suprabasal layers; all of the basal layer clear cells as seen with conventional staining routines are melanocytes, (Breathnach, 1980). They cannot be observed quite commonly in the basal layer by both light and electron microscopy. He added, that the term "nonkeratinocytes" specifies an epidermal cell that is not of prime ectodermal lineage and that does not undergo keratinization or desquamation. On the other hand Snell (1964) stated that the dendritic cells in the basal layer of epidermis of the black guinea-pig could be 
recognized by the fact that they were lying free between adjacent keratinocytes and the basement membrane and did not possess desmosomes or hemi-desmosomes. The cytoplasm contained notonofilaments but many mitochondria and there was a well-developed Golgi complex. He added that they were non-pigmented cell with a deeply indented nucleus and characteristic rod-shaped granules in the cytoplasm. The dendritic processes were well developed. Jimbow et al., (1969) distinguished them from surrounding keratinocytes by the clear cytoplasm, devoid of tonofilaments and the absence of desmosomes along the plasma membrane, as well as the indented nucleus, and numerous rod and racquet-shaped granules. Some of these rod-shaped granules open to the extra cellular spaces. The Birbeck granules are membrane bound, rod shaped 15-50 nm long, 4 $\mathrm{nm}$ wide, with a central linear density and faint striations radiating from the linear density to the limiting membrane. Those granules are of unknown function. These granules are also called Langerhans granules and vermiform granules. Langerhans cells participate in the cutaneous immune response and migrate from skin to lymph nodes. They possess surface receptors common to macrophages and function as antigen presenting cells to $\mathrm{T}$ or $\mathrm{B}$ lymphocytes. Langerhans cell serves to fix and process cutaneous antigens (Siena et al., 1995).Ginhoux et al., (2006) reported that Langerhans cell are stem cells that originate from pluripotent hematopoietic progenitor cells in the bone marrow. As immature cells Langerhans cell migrate to non- lymphatic tissues, such as skin, where they finish their maturation by expression of specific molecules and formation of the Birbeck granules (Koch et al. 2006). The Birbeck granules, characteristic structures in the Langerhans cell, are described as para-crystalline, membrane-bound, disc-shaped bodies, located preferentially between the cell membrane and the Golgi apparatus (Holibka 1998). Langerhans cells belong to the skinassociated lymphatic tissue (SALT), (Streilein et al., 1999). They are antigen presenting cells derived from monocyte precursors in the bone marrow (Gorosova et al., 2008). Exposure to ultraviolet- $B$ radiation impairs cellular immune responses. This immunosupression seems to be associated with Langerhans cell migration (Kolgen et al., 2003). The immunosupression caused by ultraviolet radiation is associated with the disappearance of antigen-presenting cells (Langerhans cells) from the epidermis (Sontag et al., 1995).

\section{Aim}

Despite the work that has been done in other species, there is insufficient information about camel nonkeratinocytes, their migration and location in the skin. Therefore this study aimed to demonstrate the distribution and locations of Melanocytes, Merkel cells, and Langerhans cells in the skin of the camel in or- 
der to better understand their ultrastructure and their involvement in the skin function and protection of camel related to the desert environment. This understanding may have significance in veterinary therapies for this species, an economically important one in the Middle East.

\section{Material and Methods}

The present study was done on the skin of five male Egyptian camels (Camelus dromedarius) of $10-15$ years'age and five male camels of 3-5 years' age. The specimens were collected from Kom-Hamada slaughterhouse. Specimens were taken from examined camels for any pathological changes and only the apparently healthy ones were selected. Specimens were mainly taken from the sides of the back portion $10 \mathrm{~cm}$ under the hump.

Fresh skin samples were collected, fixed in $10 \%$ buffered neutral formaldehyde (Bancroft and Stevens, 1979) for 48 hours, and then dehydrated in ascending grades of ethyl alcohol. They were cleared in $x y-$ lene and embedded in 3 changes of paraffin wax. The paraffin blocks were cut at 5 um thickness and stained by hematoxylin and eosin (Harris, 1900).

Pieces of $1 \mathrm{MM}^{2}$ were cut from the skin and quickly fixed in $6 \%$ solution of phosphate buffered gluteraldehyde $\mathrm{pH} 7.4$ for $6 \mathrm{hrs}$. at $4^{\circ} \mathrm{C}$, (McDowell and Trump, 1976).
After initial fixation, the tissues were washed in several changes of cold $\left(4^{\circ} \mathrm{C}\right) 0.1 \mathrm{M}$ phosphate buffer every 15 minutes for 2 hrs.

The tissues were post fixed in a $1 \%$ solution of osmium tetroxide in cold $\left(4^{\circ} \mathrm{C}\right) 0.1 \mathrm{M}$ buffer $\mathrm{pH} 7.2$ for 2 hrs. Then, they were rapidly dehydrated through ascending grades of ethyl alcohol then transferred to propylene oxide and placed in a 1:1 mixture of propylene oxide and epoxy araldite, (Hayat, 1986).

Semi- thin sections $(1 \mu \mathrm{m})$ were cut firstly and stained with toludine blue and viewed with light microscope to select the suitable areas for the electron microscope examination.

The ultrathin sections $(60-100 \mathrm{~nm})$ were cut by a glass knife with LKB microtome, and then they were stained with uranyl acetate followed by lead citrate (Hayat, 1986). These sections were examined with Joel $100 \mathrm{CX}$ electron microscope operating at $80 \mathrm{Kv}$.

\section{Results}

Melanocytes of the camel epidermis were spherical to oval in shape and located mainly in the basal layer of the epidermis. They had branching processes extended between neighboring keratinocytes (Fig.3). The cytoplasm of the melanocytes had numerous melanin granules (Fig.1) with different shapes and electron densities. Some granules were oval in shape and others were elongated. Three types of melanin granules could be recognized: elec- 
tron dense granules, electron lucent granules, and mixed granules containing electron dense and electron lucent particles (Fig.4). Some melanin granules were surrounded by a halo of ribosomes (Fig.5). Sometimes melanin granules could be observed among tonofilaments of keratinocytes, and a few of them were enclosed by a membrane (Fig.6). Free ribosomes and some rough endoplasmic reticulum were observed in the cytoplasm of melanocytes (Fig.5). No desmosomes could be seen between melanocytes. The nuclei of melanocytes were oval in shape with clumps of condensed chromatin and indented nuclear envelop (Fig.7). There was no difference in the shape and structure of melanocytes in young and adult camel skin except the higher number of cells in the adult camel skin (Fig.1) compared to young camel skin (Fig.2) and the more numerous melanin granules in the adult melanocytes (Fig.8).

Merkel cells were oval or rounded and mainly located in the basal layer of the epidermis. Merkel cells were unstained with light cytoplasm (Fig.1). Some free ribosomes, mitochondria, lysosomes and vacuoles could be seen in the cytoplasm of Merkel cell. Occasionally we could find melanin granules, mainly in adult camels (Fig. 9\&10). The nuclei were ovoid with some lobulations which were more clear in the adult animals as well. Merkel cell granules were electron dense cored and membrane bounded, were relatively uniform and mainly concen-

J. Vet. Anat. trated at the periphery of the cytoplasm (Fig.11). These granules were few in young aged skin and numerous in aged ones. Intranuclear rodlets could be seen mainly in young camel skin (Fig.12).

Cytoplasmic extensions of Merkel cells were short. The cytoplasm contained dense-cored granules mainly concentrated in the cytoplasmic processes. Round perinuclear aggregates of cytoplasmic intermediate filaments and microfilaments may be seen (Fig.13).

Langerhans cells were located basally and suprabasally in the epidermis (Figs.1\&2). Their cytoplasm was electron lucent, lacked tonofilaments and no desmosomes could be seen along the cell membrane (Fig.14). The cytoplasm contained specific granules with a trilaminarmembrane. These granules were mainly seen in cross section and sometimes in longitudinal section (Figs.15\&17). The cytoplasm contained the usual cell organelles such as mitochondria, Golgi apparatus, lysosomes, rough endoplasmic reticulum and free ribosomes (Fig.16). Langerhans cell granules were mainly found in the periphery of the cells. No melanin granules could be seen in the cytoplasm. Cytoplasmic processes were observed in the intercellular spaces between keratinocytes and recognized by the light cytoplasm. The nuclei of Langerhans cells were ovoid, indented or kidney-shaped and sometimes lobulated (Fig.18\&19). The cells of adult epidermis did not differ too much from those in the young ani- 
mals, but the number of cells in adult skin was greater than that in young ones, and the oval or sometimes round nuclei were seen only in adult skin (Fig.19).

\section{Discussion}

In the present study we found that melanocytes of the epidermis of young and adult camel were spherical and oval in shape and located in the basal layer of epidermis. In human skin, Yamaguchi (2007) observed that melanocytes were localized at the dermal / epidermal border in a regularly dispersed pattern, each melanocyte in the basal layer of the epidermis functionally connected to underlying fibroblasts in the dermis and to keratinocytes.

Melanocytes of young and adult camels had several processes containing numerous melanin granules extended between neighboring keratinocytes. Snell and Bischitz (1959) found the same results in Guinea pig epidermis in which dendritic processes of melanocytes were sandwiched between adjacent keratinocytes.

No desmosomes were found between melanocytes and adjacent cells, Birbeck (1962) revealed that the absence of desmosomes and lack of adhesions between melanocytes and adjacent cells might be explained by melanocytes' thrusting their processes between keratinocytes. We detected some melanin granules among tonofilaments of keratinocytes. Charles and Ingram(1959), postulated a cytocrine

J. Vet. Anat. secretion of melanin granules from the melanocytes to keratinocytes secondary to the breakdown of cell membrane.

We observed that melanin granules had different shapes and densities. Electron dense granules and mixed granules containing electron dense and electron lucent parts (in addition to electron lucent granules) were found in young and adult camel skin. Charles and Ingram(1959) noticed in human melanocytes a periodic structure in granules consisting of alternating dense and light bands.

The most important mechanism of skin protection from UV rays is stratum corneum thickening and melanin synthesis by melanocytes (Diffey, 1997 and Watab et al., 2004). This presumably explains the increased number of melanocytes in adult camels and also the numerous melanin granules at this age. An older animal is subjected to a lot of sun light during the long sunny days in the desert environment. Because UV radiation leads to the increasing of differentiated melanocytes in skin by the induction of tyrosinase, it can also be predicted that mitotic melanocytes activity is accelerated (Magnus, 1976).

In this study Merkel cells were clear oval or rounded cells and mainly located near the basal layer of the epidermis. Hashimoto, (1972) reported that Merkel cells might found individually in the basal layer of epidermis or occasionally above the basal layer. He added that the nuc- 
leus was usually lobulated and in our study, the nuclei were ovoid with some lobulations which were clearer in the adult age.

The intranuclear rodlet of the Merkel cell, which was first described by Fortman \& Winkelmann (1973), is similar to that of other neuronal cells. They were rarely seen in the nuclei of Merkel cells, and then only in young camel skin and could not be found in adult camel skin.

Merkel cell granules were electron dense and membrane bounded, relatively uniform and mainly concentrated in the cell side and in the cytoplasmic processes. These granules were few in young skin and numerous in old ones. These granules were recorded by Hashimoto, (1972) and described as membrane -surrounded dense granules which may be derived from Golgi saccules. Troy and Callender, (1994) found that the dense-cored granules of Merkel cells were characteristically concentrated in the cytoplasmic processes of the cells, while Breathnach and Robins, (1970) \& Halata et al., (2003) found that they were accumulated near the junction with the nerve fiber. In our study we could not find nerve fiber attachment with the epidermal Merkel cells as which previously reported by Halata \& Munger, (1981) when they found the same result, on very rare occasions in dermal Merkel cells. This may suggest that epidermal Merkel cells of camel may be not largely involved as mechanoreceptors and they may be acting mainly as endocrine cells. Cells in the skin with a similar appearance as Merkel cells, but without contact to nerve terminals, are probably part of a diffuse neuroendocrine system and do not function as mechanoreceptors. Probably these cells rather than those acting as mechanoreceptors are the origin of a highly malignant skin cancer (Halata et al., 2003). The Merkel cell was presumed to be involved in not only mechanoreception but also endocrine or paracrine functions (Yoshie et al., 1990).

On the other hand, Moll et al., (1986) suggested that in subsequent stages of skin development some epidermal Merkel cells detach from the epithelium and migrate into the upper dermis where some of them may associate with small nerves.

In this study, occasionally we could find melanin granules in the cytoplasm of Merkel cells, and this agreed with Hashimoto, (1972) who reported that Merkel cells contained lysosome-like dense bodies and transferred to melanosomes.

The surface of Merkel cells is equipped with protoplasmic protrusions anchoring them between keratinocytes (Halata and Baumann, 2000) and this agreed with the results obtained in this study in which Merkel cells of camel epidermis had short cytoplasmic processes intertwined in between the keratinocytes. These appeared as light areas of cytoplasm containing the densecored granules. 
Occasional desmosomes might connect the Merkel cell to the neighboring keratinocytes in camel epidermis. This result agreed with the result of Hashimoto, (1972). The presence of desmosomal contacts between Merkel cells and keratinocytes was interpreted as support for the ectodermal origin hypothesis of Merkel cells (Munger, 1965). Merkel cells were also highly adapted for detection of movement in adjacent keratinocytes, as well as movement of the epithelium with respect to underlying connective tissue, (Garant et al., 1979).

Langerhans cells of the epidermis of camel were similar to those described in other mammals (HollisandLyne, 1972; Wolff, 1972; Khalil et al., 1982 and Romano and Balaguer, 1991) including the electron lucent cytoplasm, without tonofilaments, desmosomes or melanosomes with a dendritic processes and the indented or occasionally lobulated nucleus. Langerhans cells of camel were located in the basal and suprabasal layer of the epidermis and this agreed with Khalil et al., (1982) in cattle skin; and Romano and Balaguer (1991) in swine skin, but disagreed with the result of Hollis and Lyne (1972) in sheep skin where it observed only in the basal layer.

Romano and Balaguer (1991) observed that swine epidermal Langerhans cells possessed the specific trilaminar rod or racquet-shaped (Birbeck) granules in varying numbers, but not as numerous as those reported in man. On the other hand, in our study the Langerhans cell granules were found in the skin of camels but not with a clear racquet shape. We reported only rod shaped granules with cross and longitudinal sections with a trilaminar membrane. So we suggest that camel skin has rod shaped Langerhans cell granules. No single descriptive term could explain the full range of shapes assumed by the granules of Langerhans cell. Therefore, a more adequate term would be simply "Langerhans cell granule" which implies the variety of shapes that might be encountered (Sagebiel and Reed,1968). In camel skin Langerhans cells granules were not numerous and may be fewer in number than those of swine as described by Romano and Balaguer (1991). The low number might be due to the UV rays in the desert environment in which the camel lived. Silberberg et al., (1976) found that Langerhans cells migrate from skin to lymph nodes under normal conditions and this migration may be accelerated in an immune reaction. According to Oaklander et al., (2003),the number of Langerhans cells reportedly increased in inflamed human skin and it was not known whether this increase occurred when chronic pain was due to neural injury rather than tissue injury. He added that the Langerhans cell count did not vary according to gender and age. Loss of epidermal innervations did not influence the number of Langerhans cells. While studies in humans had shown a decreased Langerhans cell 
density with age, it is difficult to control for the effect of ultraviolet light in human studies, since ultraviolet light has a significant effect on Langerhans cells (Choi and Sauder, 1987). Bacci et al., (2001) gave a possible explanation that ultraviolet rays impair ultraviolet $B$ radiation susceptible mice by immobilizing Langerhans cells transiently in the epidermis and upper dermis, thereby preventing their timely migration to draining lymph nodes.

The number of Langerhans cells in adult camel skin was greater than that of young ones but this result disagreed with the result of Choi and Sauder (1987), where they found that aged mice had approximately two-thirds the number of Langerhans cells that young animals did. Although the aged animals demonstrated increased variability in their responsiveness there was no overall difference in cutaneous immunoreactivity between the two age groups.

Oaklander et al., (2003) said that the number of Langerhans cells is unrelated to the presence or severity of pain, while Oota (1999) showed that Langerhans cells play an essential role in the differentiation of the epidermis. On the other hand, Gorosova et al., (2008) found that Langerhans cells seem to participate in skin disorders related to hypersensitivity and even tumor transformations. Distribution of these cells may play a role in disease predispositions and knowledge of the physiology and pathophysiology of Langerhans cells opens possible targeted treatments in veterinary medicine.

\section{Conclusion}

From this study we can conclude that:

1- Melanocytes of camel skin are more numerous in adult camels than in young ones, with a higher number of melanin granules in adults; and this suggests a skin protection mechanism from the excessive ultraviolet rays from the sun light in the desert which increases melanocyte differentiation and accelerates their mitotic activity.

2- Merkel cells of camel skin had lobulated nuclei mainly in adult camels, which had also a higher number of dense cored granules than the young one. But intranuclearrodlets were observed only in young camel skin which in addition to the absence of nerve endings suggests that Merkel cells of camel are not largely involved as mechanoreceptors but are more likely endocrine cells.

3- The Langerhans cells of adult camel skin were greater in number than in young ones and this may be due to the bad effect of the ultraviolet rays with a long exposure time. Round nuclei were seen only in adult skin. Langerhans cell granules were detected but without a clear 
racquet shape, so they might be rod shaped only; and they were surrounded by a trilaminar membrane. The Langerhans cell granules were few in number and this might suggest the harmful effect of the ultraviolet rays of the Egyptian desert environment.

\section{References}

Bacci, S.; Alard, P. and Streilein, J.W. (2001): Evidence that ultraviolet $\mathrm{B}$ radiation transiently inhibits emigration of Langerhans cells from exposed epidermis, thwarting contact hypersensitivity induction. Eur J Immunol., 31 (12): 3588-94.

Bancroft, J.D. and Steven, A.

(1979): Theory and practice of histological techniques. $2^{\text {nd }}$ ed. Churchill Livingstone, Edinburg, London New York.

Birbeck, M. (1962): Electron microscopy of melanocytes. Brit.

Med. Bull. Vol.(18) No.(3) pp.220-222.

Breathnach, A.S. (1980): Branched cells in the epidermis: An overview. Journal of Investigative Dermatology, 75: 611.

Breathnach, A. S. and Robins, J.

(1970): Ultrastructural observations on Merkel cells in human fetal skin. Journal of Anatomy 106, 411.

Charles, A. and Ingram, J. (1959):

Electron microscopic observation of the melanocytes of the human epidermis . J. Biophys. Biochem. Cytol.6:4144.

Choi, k.L. and Sauder, D.N.

(1987): Epidermal Langerhans cell density and contact sensitivity in young and aged $\mathrm{BALB} / \mathrm{c}$ mice. Mech Ageing Dev, 39 (1): 69-79.

Diffey, BL.(1997): Dosimetry of the ultraviolet radiation in: Lowe NJ, Shoath NA, Pathak MA. editors, Development evaluation and regulatory aspects, $2^{\text {nd }}$ NewYork. pp 175-188.

Fortman, G. J. and Winkelmann,

R. K. (1973) : A Merkel cell nuclear inclusion. Journal of Investigative Dermatology 61, 334-338.

Frappier,B. and Eurell,J.(2006):

Dellmann's textbook of veterinary histology, sixth edition. Blackwell publishing.

Garant, P.R.; Feldman, M.I.; and Cho, M.R. (1979): Ultrastructure of Merkel cells in the hard palate of the squirrel monkey (Saimiri sciureus). American Journal of Anatomy, 157 (2): 155-167.

Ghobrial, L.I. (1970): Acomparative study of the integument of the camel, Dorcas gazelle and jerboa in relation to desert life. J. Zool. Lond., 160: 509-521.

Ginhoux, F.;Tacke, F.; Angeli, V.; Bogunovic, M.; Loubeau, M.; Dai, X.M.; Stanley, E.R.; Randolph, G.J.; and Merad, M. (2006): Langerhans cells arise from monocytes in vi- 
vo. Nat Immunol., 7: 265273.

Gorosova, A.; Matalova, E.; Koci anova, I.; and Tichy, F. (2008): Langerhans cells in feline foetal epidermis-immunohistochemical study of spatial distribution. Acta Vet. Brno, 77:307-312.

Halata, Z. and Baumann, K.I. (2000): Topography of nerve terminals in Merkel nerve endings in mammals. In: Suzuki $\mathrm{H}$, Ono $\mathrm{T}$ (eds) Merkel cells, Merkel cell carcinoma and neurobiology of the skin. Elsevier, Amsterdam: 33-42

Halata, Z. \& Munger, B. L. (1981):

Identification of the Ruffini corpuscle in human hairy skin. Cell and Tissue Research, 219: 437-440.

Halata, Z.; Grim, M.; and Bauman,

K. (2003): Friedrich Sigmund Merkel and his (Merkel cell), morphology, development, and physiology: review and new results. The Anatomical Record, 271 (A): 225-239.

Harris, H.F. (1900): The haematox ylin: In: Theory and Practice of Histological Techniques. Colchester and London.

Hayat, M. (1986): Basic Technique for Transmission Electron Microscope.Academic press, Baltimore, $2^{\text {nd }} E d$.

Hartschuh, W. and Weihe, E.

(1980): Fine structural analysis of the synaptic junction of Merkel cell-axon-complexus. The Journal of Investigative Dermatology, 75: 159-165.
Hashimoto, K. (1970): Lanthanum staining of Langerhans' cell. Communication of Langerhans' cell granules with extracellular space. Arch Dermatol., 102 (3): 280-290.

Hashimoto, K. (1972a): Fine structure of Merkel cell in human oral mucosa. Journal of Investigative Dermatology, 58: 381-387.

Hearing, V.; Phillips, P.; and

Lutzner, M. (1973): The fine structure of melanogenesis in coat colour mutants of the mouse. J Ultrastruct. Res., 93:88-106.

Holibka, V. (1998): Langerhans cells in the epithetlium of the human palatine tonsil during the prenatal development. Acta Univ. Palacki OlomucFac. Med., 141: 41-43.

Hollis, D.E. and Lyne, A.G. (1972):

Acetylcholinesterase-positive Langerhans cells in the epidermis and wool follicles of the sheep. Journal of Investigative Dermatology, 58: 211-217.

Jimbow, K.; Sato, Syozo and Kukita, A (1969): Langerhans' cells of the normal human pilosebaceous system. An electron microscopic investigation. The Journal of Investigative Dermatology, 52 (2): 177-180.

Jimbow, K.;Oikawa, O.; Sugiyama S. and Takeuchi T. (1979): Comparison of eumelanogenesis and pheomelanogenesis in retinal and follicular melanocytes; role of vesi- 
culo-globular bodies in melanosome differentiation. J Invest Dermatol73: 278-284.

Kaur, P. (2006): Interfollicular

epidermal stem cells: Identification, challenges, potential. J Invest Dermatol., 126: 1450-1458.

Khalil, M.M.; Nitiuthai, S. and Al len, J.R. (1982): Alkaline phosphatase positive Langerhans cells in the epidermis of cattle. Journal of Investigative Dermatology, 79 : 47-51.

Koch, S.; Kohl, K.; Kleine, E.; Von Bubnoff, D.; and Bieber, T. (2006): Skin homing of Langerhans cell precursors: adhesion, chemotaxis, and migration. J Allergy Clin Immunol., 117: 163-168.

Kolgen, W.; Van Steeg, H.; Horst, G.; Hoeijmakers, H.J.; Vloten, W.A.; De Gruijl, F.R.; and Garssen, J. (2003): Association of transcriptioncoupled repair but not global genome repair with ultraviolet-B-induced Langerhans cell depletion and local immunosupression. The Journal of Investigative Dermatology, 121 (4): 751-756.

Lee, D.G. and Schmidt-Nielsen, K. (1962): The skin, sweat glands and hair follicles of the camel (Camelus dromedarius). Anat. Rec., 143: 7177.

Magnus, I.(1976): Dermatological photobiology. Blackwell scientific publications. pp.3540.
McDowell, A.M. and Trump, F.

(1976): Histologic fixatives suitable for diagnostic light and electron microscopy. Arch. Pathol. Lab. Med. 100: 405-415.

Moll, I.; Moll, R.; and Franke, W.W. (1986): Formation of epidermal and dermal Merkel cells during human fetal skin development. J Invest Dermatol.,87 (6): 779-87.

Moll, R.; Moll, I.; and Franke, W.W. (1984): Arch. Dermatol. Res.: 276-363.

Moll, I.; Lane, A.T.; Franke, W.W.; and Moll, R. (1990): Intraepidermal formation of Merkel cells in xenografts of human fetal skin. J Invest Dermatol.,94 (3): 359-64.

Munger, B.L. (1965): The intraepidermal innervations of the snout skin of the opossum: a light and electron microscopy study with observations on the nature of Merkel's tastzellen. Journal of Cell Biology, 16: 835-843.

Munger, B. L. (1975): Cytology of mechanoreceptors in oral mucosa and facial skin ofrhesus monkey. In The Nervous System. Vol. 1 (ed. D.B.Tower), The Basic Neurosciences. pp. 71-79. New York: Raven Press.

Munger, B. L. (1977): Neural-

Epithelial interactions in sensory receptors. Journal of Investigative Dermatology, 69: 27-49.

Nanci, A. and Tencate,R. (2008): 
Tencate'soral histology, development structure and functions. Mosby Elsevier health scence.

Niebauer,G.; Krawczyk, W.S.;

Kidd, R.L.; and Wilgram, G.F. (1969): Osmium zinc iodide reactive sites in the epidermal Langerhans cell. The Journal of Cell Bioligy, 43: 80-89.

Oaklander, A.L.,; Stocks, E.A.; and Mouton, P.R. (2003): Number of Langerhans immune cells in painful and non-painful human skin after shingles. Arch Dermatol Res. ;294(12):529-35.

Oota, S. (1999): Some new aspects of Langerhans cells in the human epidermis: Light and electron microscopic observations on the swelling sites seen in the process terminals of the dendritic cells described by Langerhans in 1868. Yonago Actamedica, 42:153-161.

Pfeiffer, C.J.; Osman, A.H.K.; and

Pfeiffer, D.C. (2006): Ultrastructural analysis of the integument of a desert-adapted mammal, the onehumped camel (Camelus dromedarius). Anat. Histol. Embryol., 35: 97-103.

Romano, J. and Balaguer, L.

(1991): Ultrastructural identification of Langerhans cells in normal swine epidermis. J. Anat., 179: 43-46.

Sagebiel, R.W. and Reed, T.H. (1968): Serial reconstruction of the characteristic granule of the Langerhans cell. The Journal of Cell Biology, 36: 595-602.

Siena, S.; Di Nicola, M.; Bregni,

M.; Mortarini, R.; Anichini, A.; Lombardi, L.; Ravagnani, F.; Parmiani, G.; and Gianni, A.M. (1995): Massive ex-vivo generation of functional dendritic cells from mobilized CD34 (+) blood progenitors for anticancer therapy. Exper. Hematol., 23 (14): 14631471.

Silberberg, S, I.; Thorbecke, G.J.; Baer, R.L.; Rosenthal, S.A.; and Berezowsky, V. (1976): Antigen bearing Langerhans cells in the skin dermal lymphatics and lymph nodes. Cell. Immunol., 25:137.

Snell, R.S. (1964): An electron mi croscopic study of the dendritic cells in the basal layer of guinea-pig epidermis. Cell and Tissue Research, 66 (3): 457-470.

Snell, R. S. and Bischitz, P. G. (1959): A study of the effect of orchidectomy on the melanocytes and melanin in the skin of the guinea-pig. Z. Zellforsch., 50: 825-834.

Sontag, Y.; Guikers, C.L.; Vink, A.A. (1995): Cells with UVspecific DNA damage are present in murine lymph nodes after in vivo UV irradiation. J Invest Dermatol, 104: 734-738.

Straile, W. E.; Tipnis, U. R.; Mann, S. J. and Clark, W. H. (1975): Lattice and rodlet nuclear inclusions in Merkel 
cells in rabbit epidermis. Journal of Investigative Dermatology, 64: 178-183.

Streilein, J.W.; Alard, P.; and

Niizeki, H. (1999): A new concept of skin-associated lymphoid tissue (SALT): UVB light impaired cutaneous immunity reveals a prominent role for cutaneous nerves. Keio J Med., 48: 2227.

Troy, A. and Callender, M.D. (1994): Merkel carcinoma cell of the skin. Bobby R. Alford Department of Otolaryngology-Head and Neck Surgery, Baylor College of Medicine.

Turner, D.F. (1982):ThemorphoLogy and distribution of Merkel cells in primate gingival mucosa. The anatomical record, 205 (2): 197-205.

Watabe,H. ;Valencia,J. ;Yasumoto,K.;Kushimoto,T. ; Ando,H. and Muler,J.(2004) : Regulation of tyrosinase processing and trafficking by organellerpH and by activity.J.Bio. ChemVol.(279).No.(9).pp 79717981.

Winkelmann, R.K. (1977): The Merkel cell system and a comparison between it and the neurosecretory or APUD cell system. J Invest Dermatol., 69 (1): 41-6.

Wolff, K. (1972): The Langerhans cell. Curr.Probl.Dermatol., 4: 79-1 45.

Yamaguchi,Y.; Brenner,M.; and Hearing,V.(2007):The regulation of skin pigmentation. Journal of Biological Chemitery. Vol. (202). No.(38). Pp: 27557-2756.

Yoshie, S.; Wakasugi, C.; Teraki, Y.; and Fujita, T. (1990) : Fine structure of the taste bud in guinea pigs. I. Cell characterization and innervation patterns. Arch Histol Cytol., 53 : 103-119. 


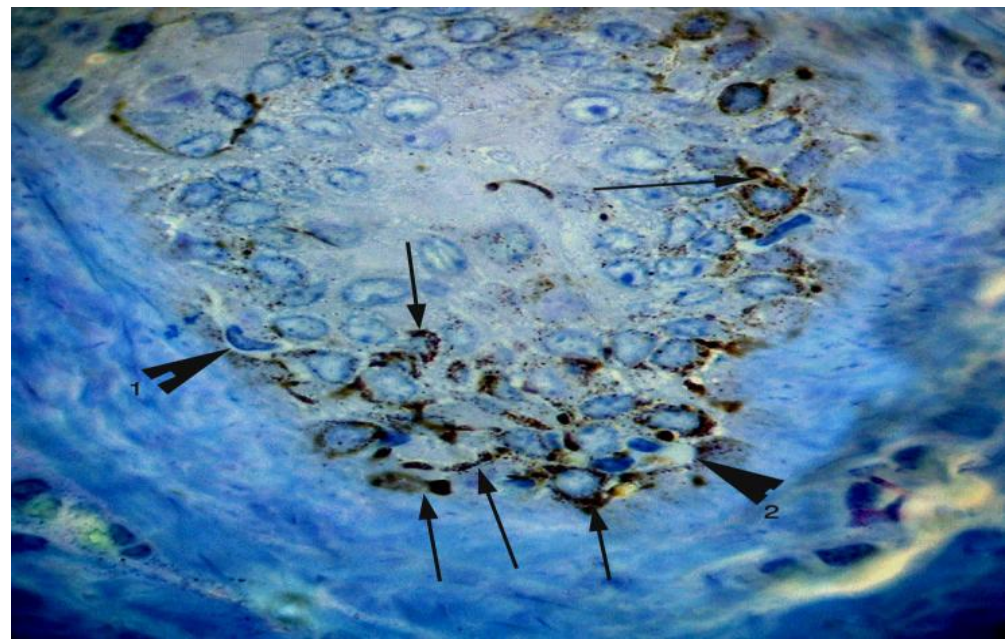

Fig (1): A photomicrograph showing the high amount of melanin granules (arrows) in the epidermis of adult skin camel, the Merkel cell (arrow head 1) and the Langerhans cell (arrow head 2). (Toludene blue stain, semithin section. Mic.Mag. X 1000).

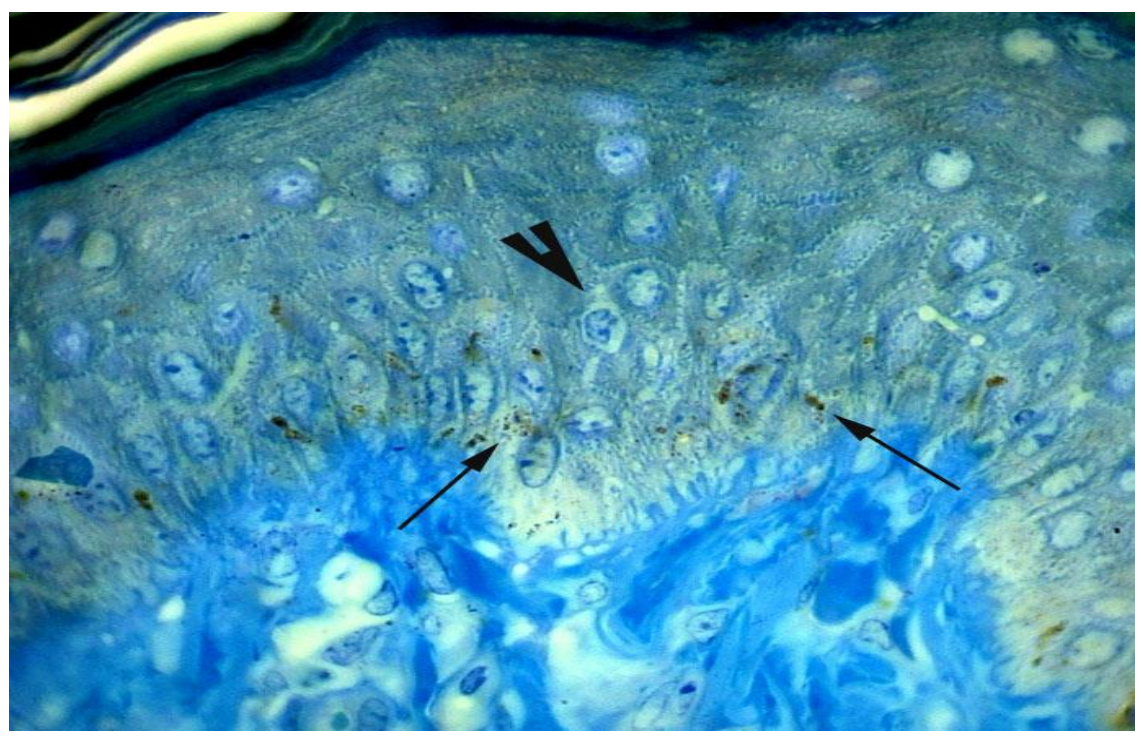

Fig (2): A photomicrograph showing the low amount of melanin granules (arrows) in the epidermis of young skin camel, and the Langerhans cell (arrow head). (Toludene blue stain, semi-thin section. Mic. Mag. X 1000). 


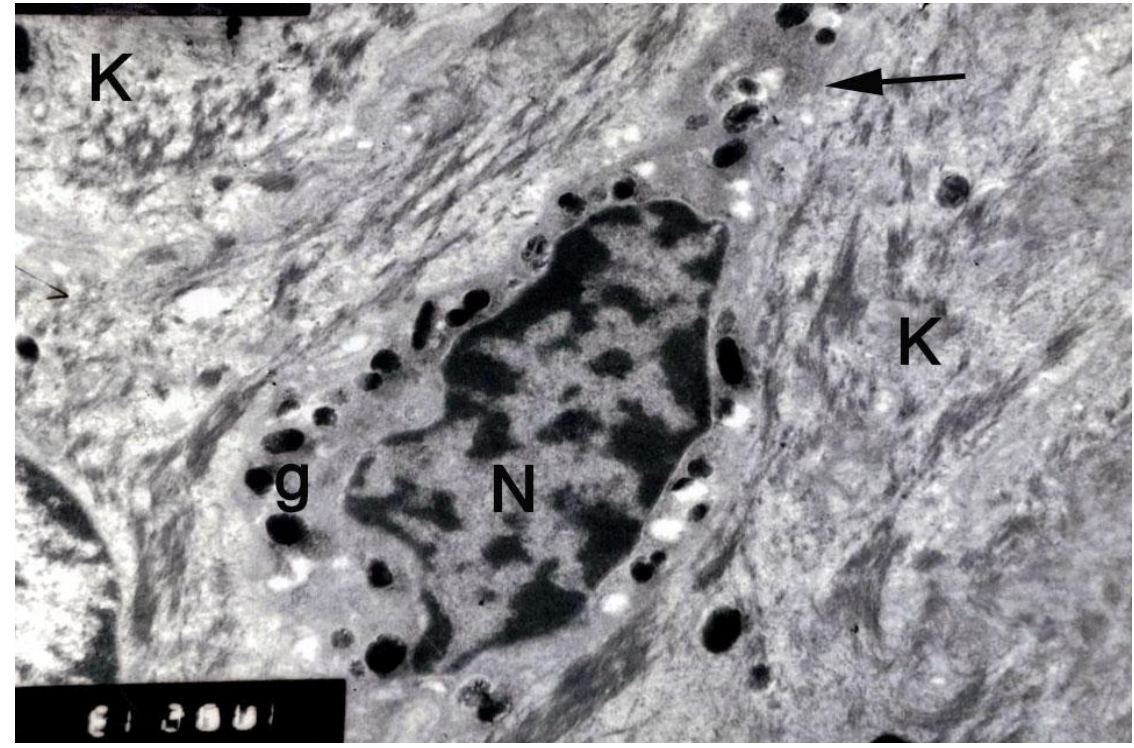

Fig (3): Transmission electron micrograph of the skin of young camel showing one melanocytes with a dendritic process (arrow). Many melanin granules (g), the nucleus of the cell $(\mathrm{N})$ and keratinocytes $(\mathrm{K})$ around it.(Mic. Mag. X 10000).

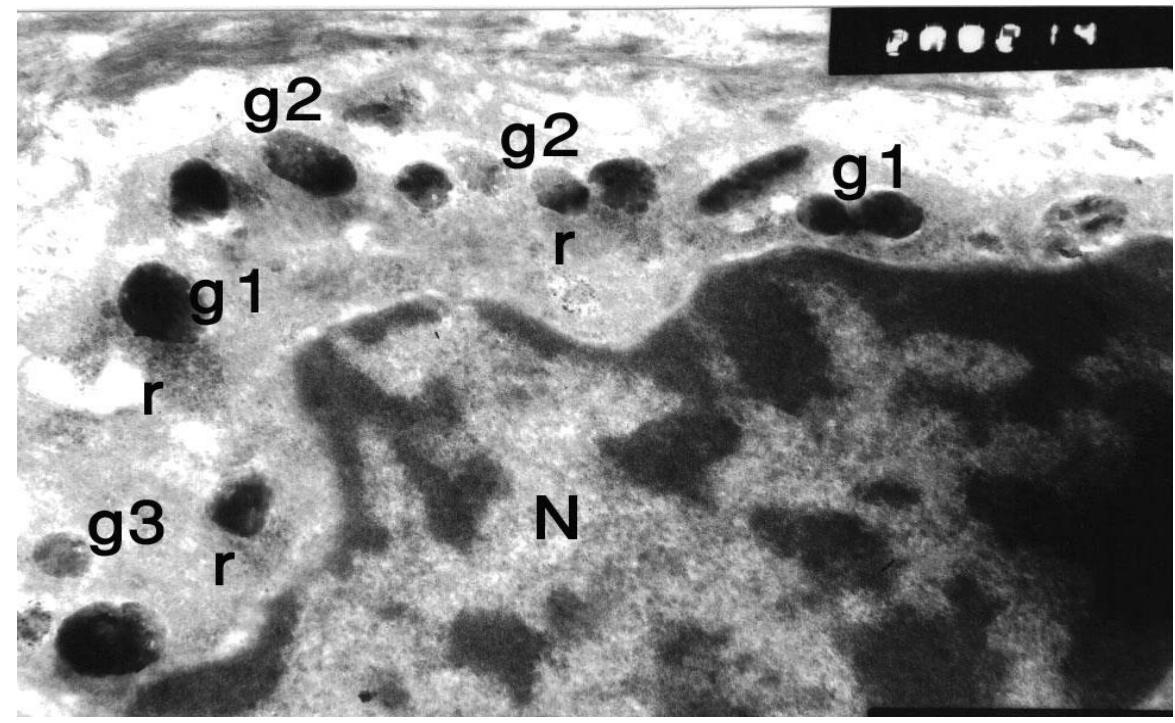

Fig(4): Higher magnification transmission electron micrograph of the previous melanocyte denoting three types of melanin granules, electron dense granules (g1), mixed melanin granules (g2) and electron lucent granules (g3). Note a hollow of ribosomes ( $r$ ) surrounding melanin granules, nucleus (N). (Mic. Mag. X 20000). 


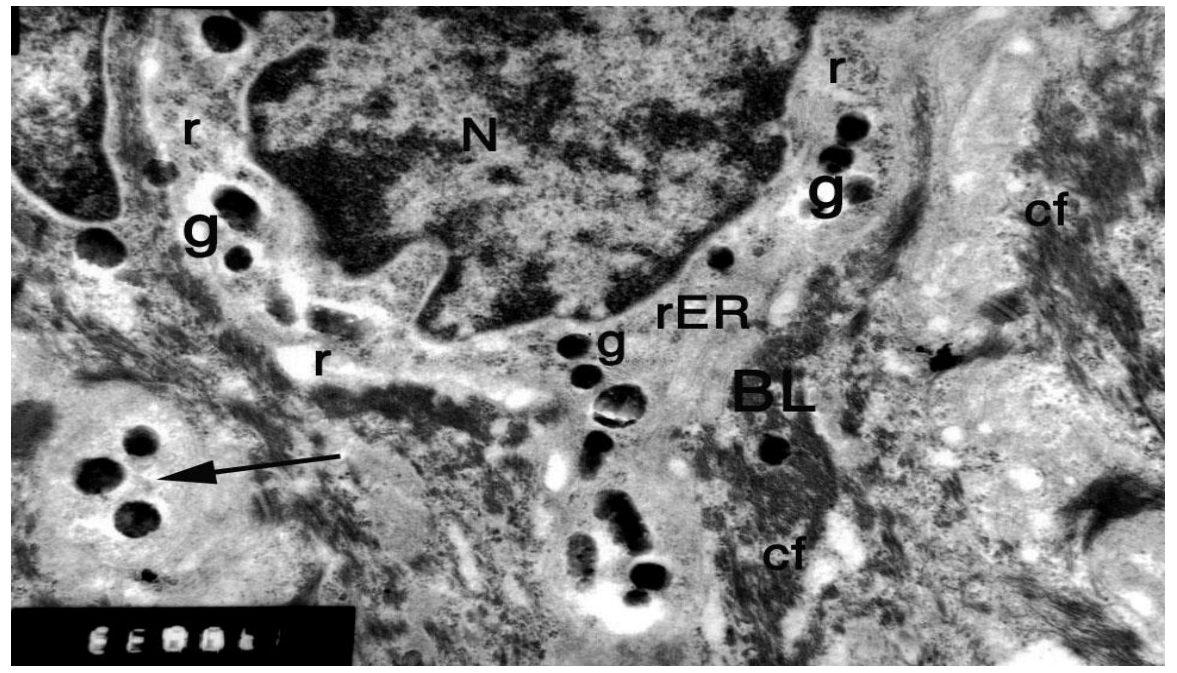

Fig(5): Transmission electron micrograph of another melanocytes in the skin of young camel, lying on the basal lamina $(\mathrm{BL})$. The cell contains numerous melanin granules $(\mathrm{g})$ of different shapes, sizes and electron densities. Few rough endoplasmic reticulum $(r E R)$ and some free ribosomes ( $r$ ) could be seen inside the cytoplasm. The cell has a cytoplasmic process (arrow) with the same granules. The nucleus $(\mathrm{N})$ is indented and collagen fibers (cf) under the basal lamina could be seen. (Mic. Mag. X 13000).

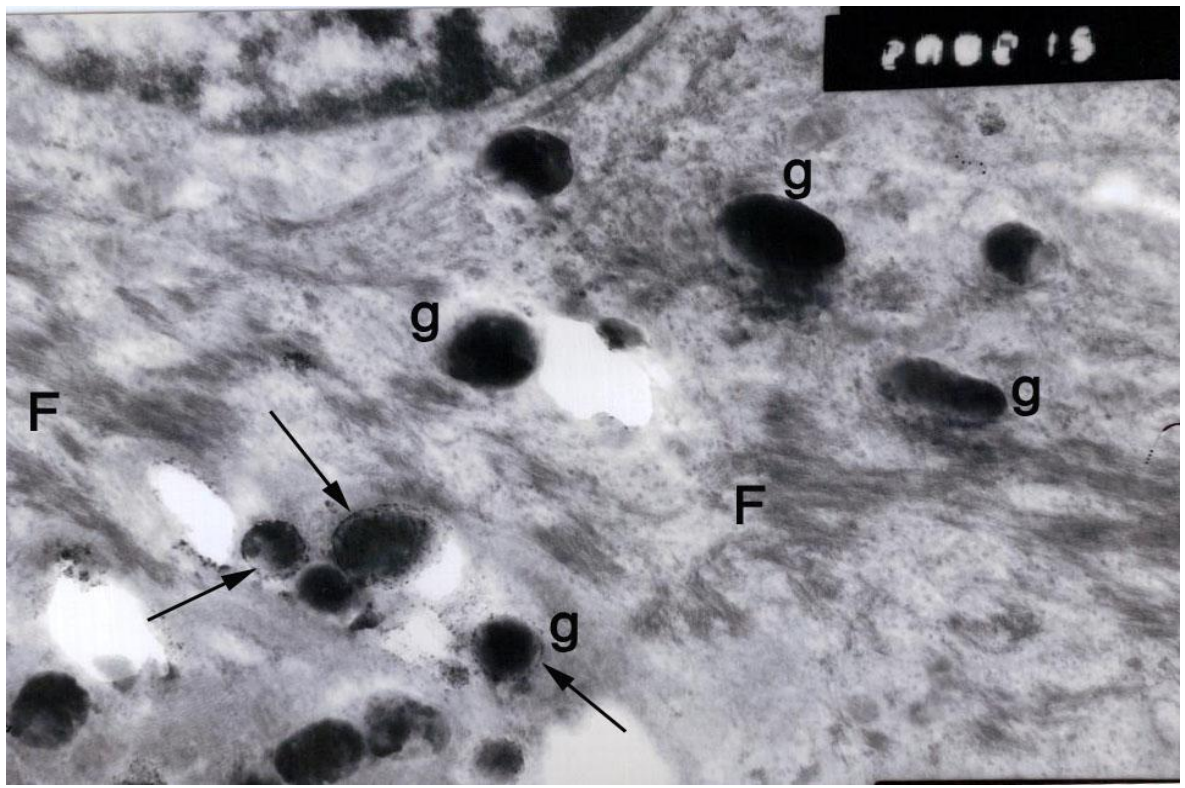

Fig (6): Transmission electron micrograph showing the lower part of one melanocytes from the skin of young camel and some melanin granules $(\mathrm{g})$ are found among the tonofilaments $(F)$ of the keratinocytes. Note that few melanin granules are enclosed by a membrane (arrows). (Mic. Mag. X 15000). 


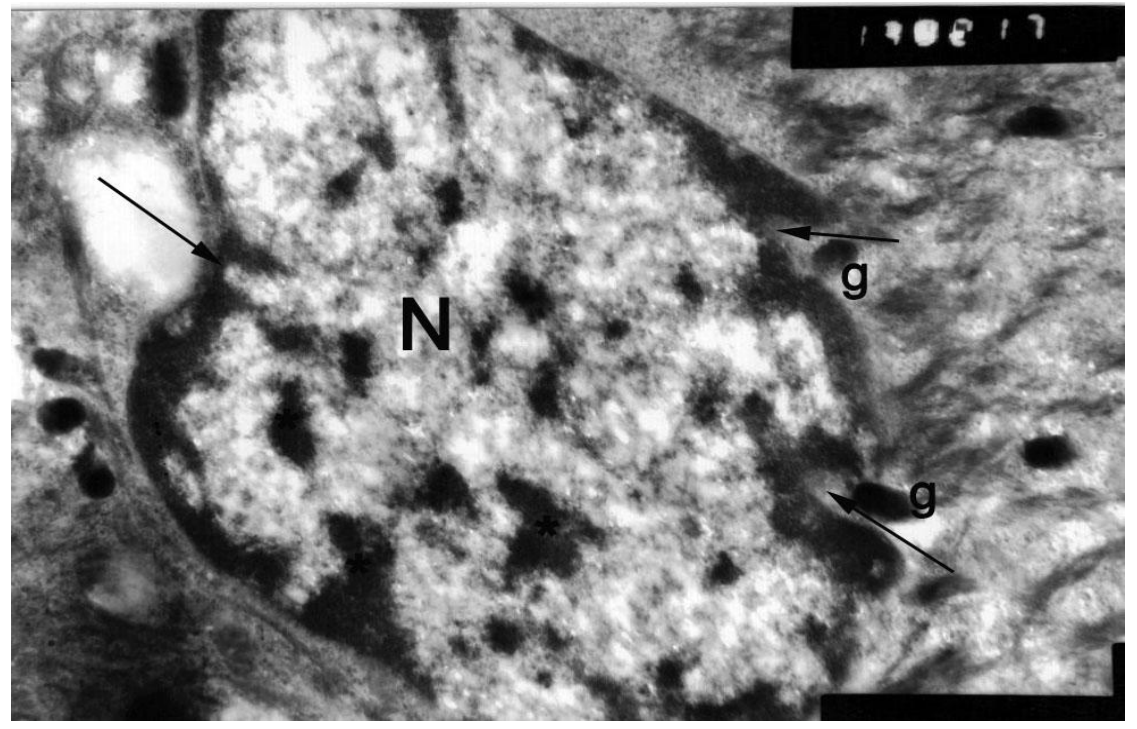

Fig (7): Transmission electron micrograph of a young camel epidermis showing a melanocytes having an oval nucleus $(\mathrm{N})$, with clumps of condensed chromatin (asterisks) and indented nuclear envelop (arrows). Few melanin granules (g) could be seen. Note the absence of desmosomes. (Mic. Mag. X 13000).

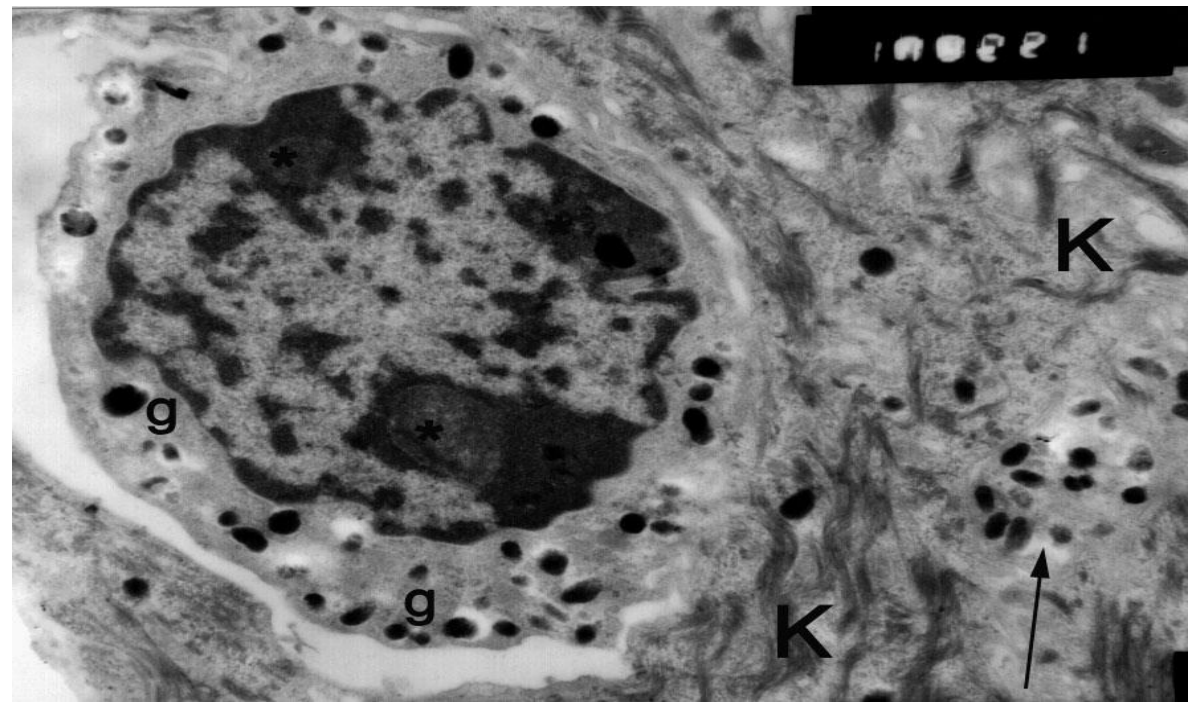

Fig (8): Transmission electron micrograph of the adult camel skin melanocytes showing numerous melanin granules ( $g$ ) of different shapes, sizes and electron densities, the nucleus having large clumps of condensed chromatin (asterisk). Cytoplasmic processes of melanocytes (arrow) are found between the keratinocytes $(K)$. No desmosomes could be found between the keratinocytes $(K)$. No desmosomes could be found between the melanocytes and the neighboring cells. (Mic. Mag. X 10000). 


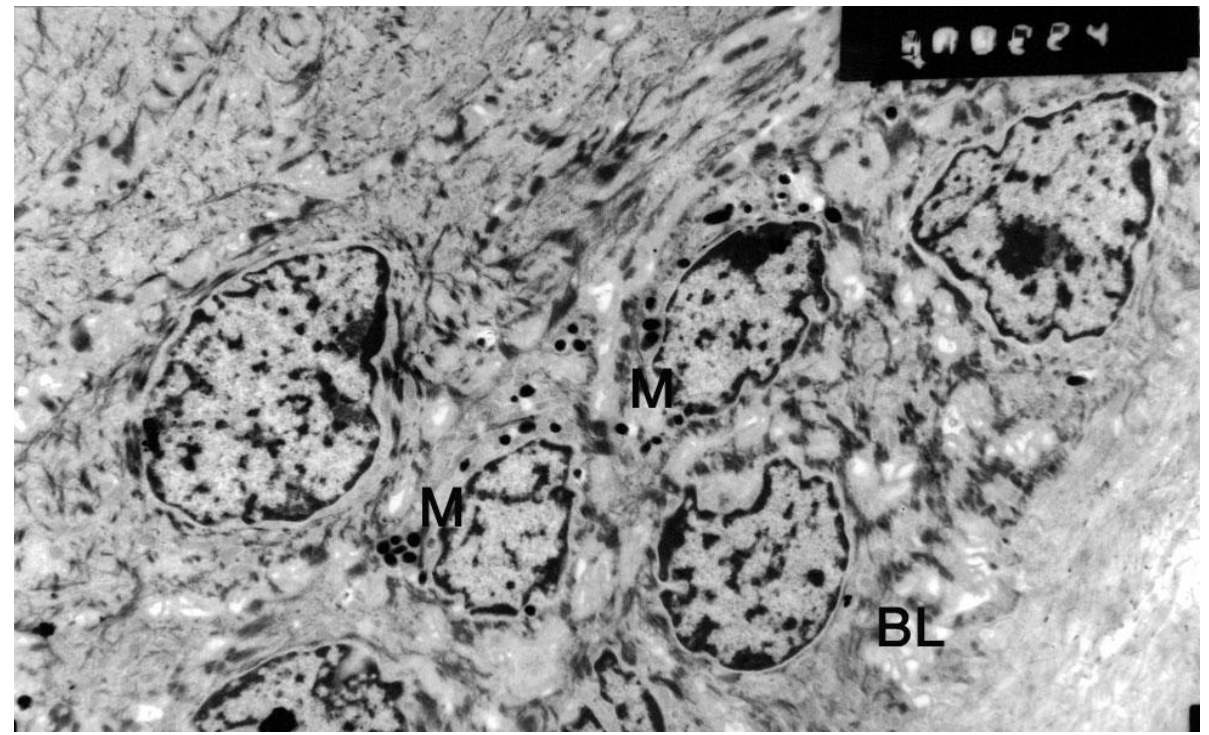

Fig (9): Transmission electron micrograph of the adult camel skin showing many epidermal cell laying on the basal lamina (BL). Two Merkel cells $(\mathrm{M})$ could be recognized from their cytoplasmic dense granules and the ovoid lobulated nuclei. (Mic. Mag. $X$ 5000).

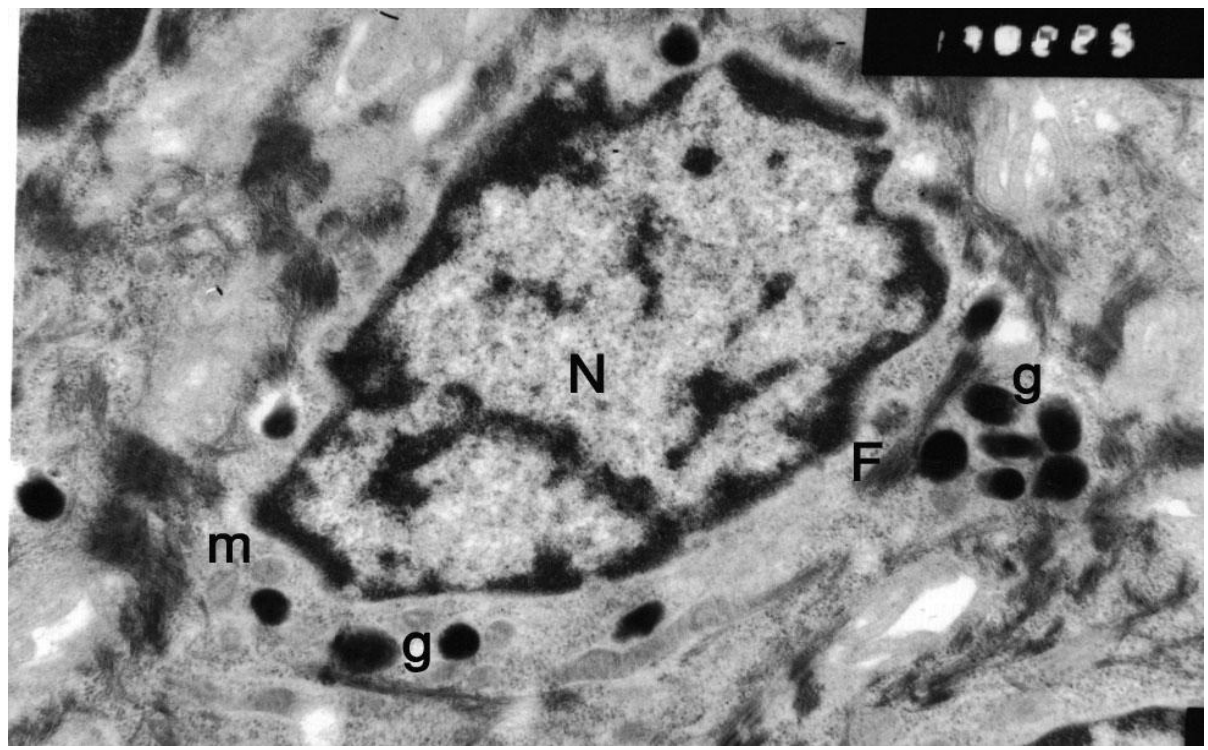

Fig (10): Transmission electron micrograph of one Merkel cell of an adult camel epidermis, showing the ovoid nucleus $(\mathrm{N})$, cytoplasmic electron dense granules $(\mathrm{g})$, some mitochondria (m) and cytoplasmic filaments (F). (Mic. Mag. $X$ 13000). 


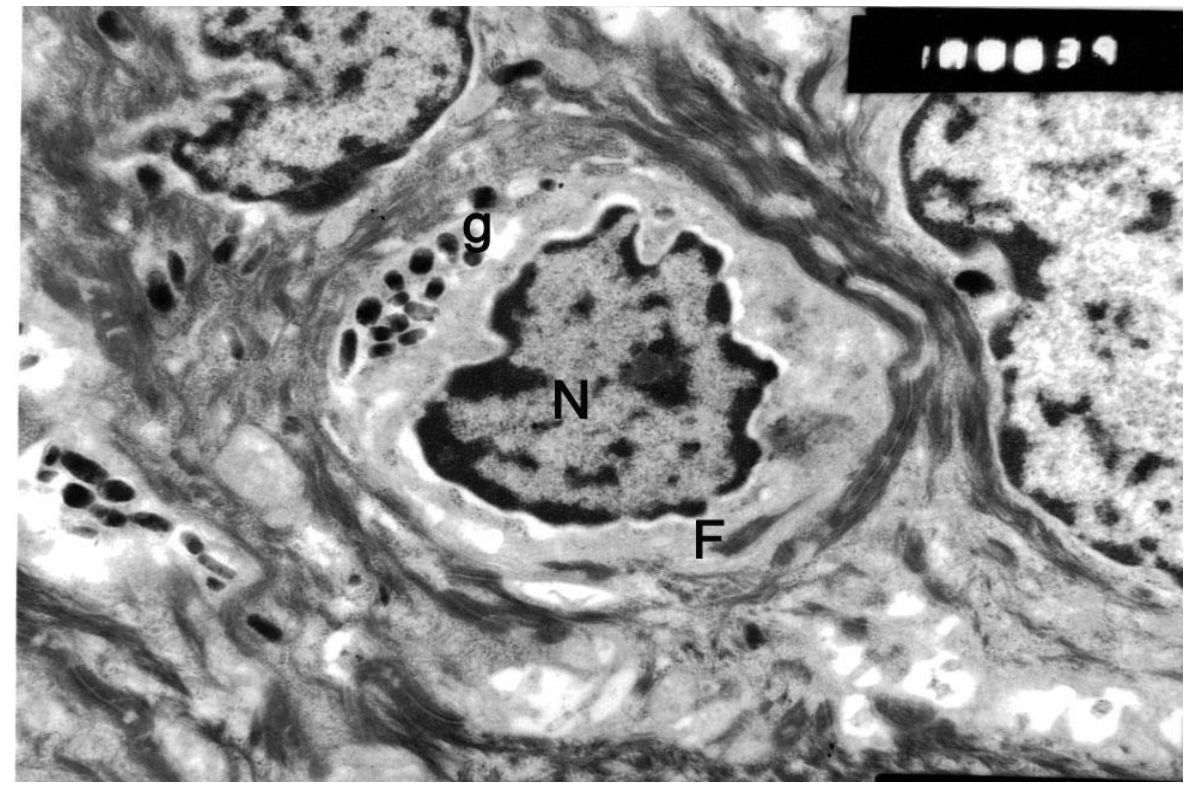

Fig (11): Transmission electron micrograph of the adult camel epidermis, showing Merkel cell with an ovoid lobulated nucleus $(N)$ and light cytoplasm. Electron dense cytoplasmic granules $(\mathrm{g})$ are found at one side of the nucleus. Cytoplasmic intermediate filaments (F).(Mic. Mag. X 10000).

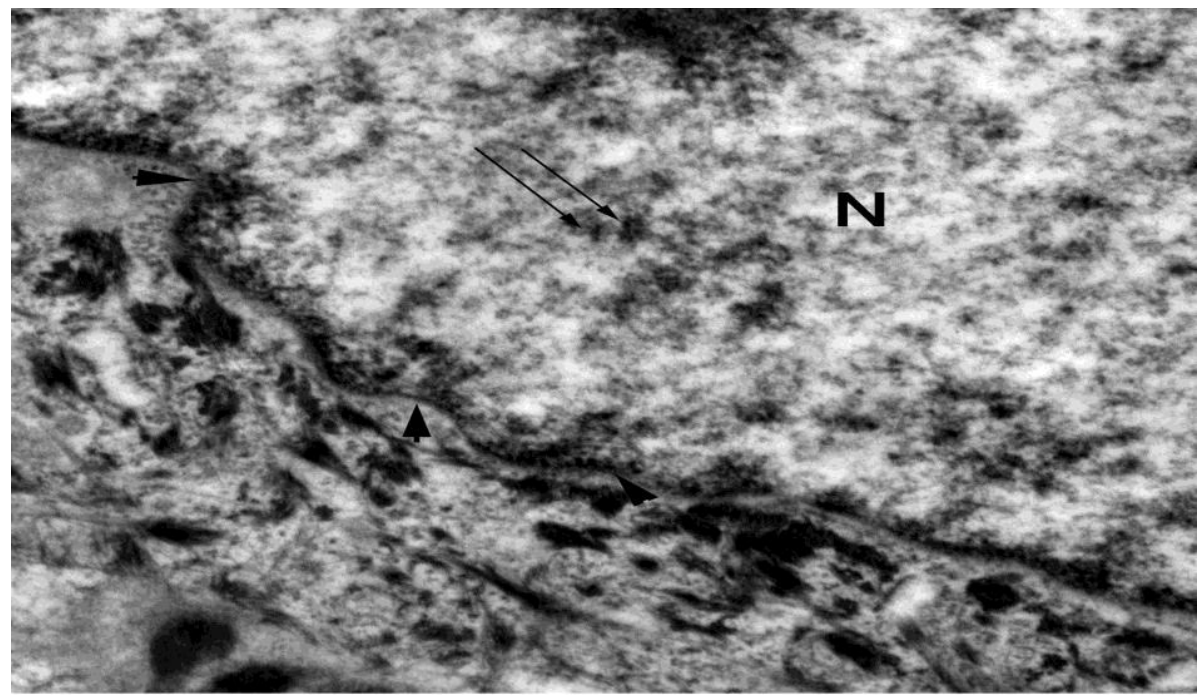

Fig (12):Transmission electron micrograph of the skin of young camel showing part of Merkel cell having a nucleus $(\mathrm{N})$ with undulated nuclear envelop (arrow heads) and two nuclear rodlet (arrows). (Mic. Mag. X 10000). 


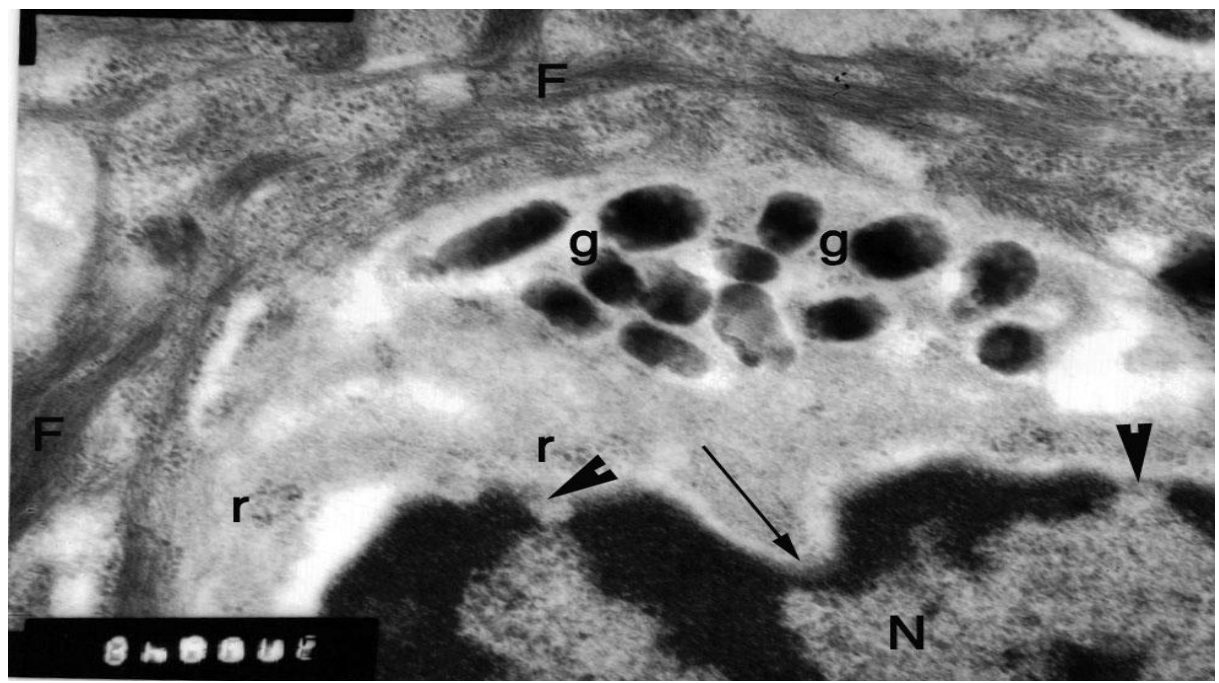

Fig(13): High magnification transmission electron micrograph of Merkel cell of adult camel epidermis, showing part of its nucleus $(\mathrm{N})$ with clear indentation (arrow), light cytoplasm with electron dense cored granules $(g)$ and free ribosomes $(r)$. Note the nuclear pores (arrow heads) and the filaments (F) of keratinocytes. (Mic. Mag. X 13000).

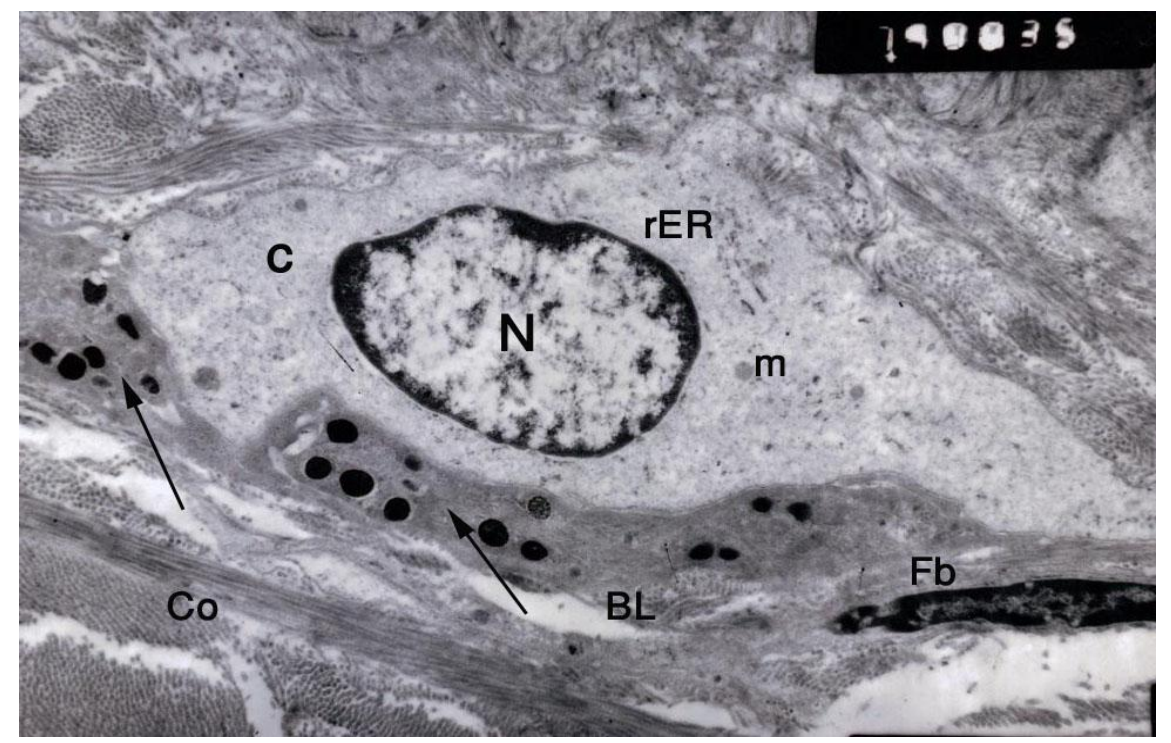

Fig (14): Transmission electron micrograph of the young camel epidermis showing Langerhans cell just above the basal lamina (BL), the cytoplasm $(C)$ is clearly light with some few mitochondria $(\mathrm{m})$ and rough endoplasmic reticulum ( $\mathrm{rER})$. The nucleus $(\mathrm{N})$ is oval. Note the dark cytoplasmic cell processes of melanocytes (arrows), the fibroblast (Fb) under the basal lamina and the collagen fibers (Co). (Mic. Mag. X 7500). 


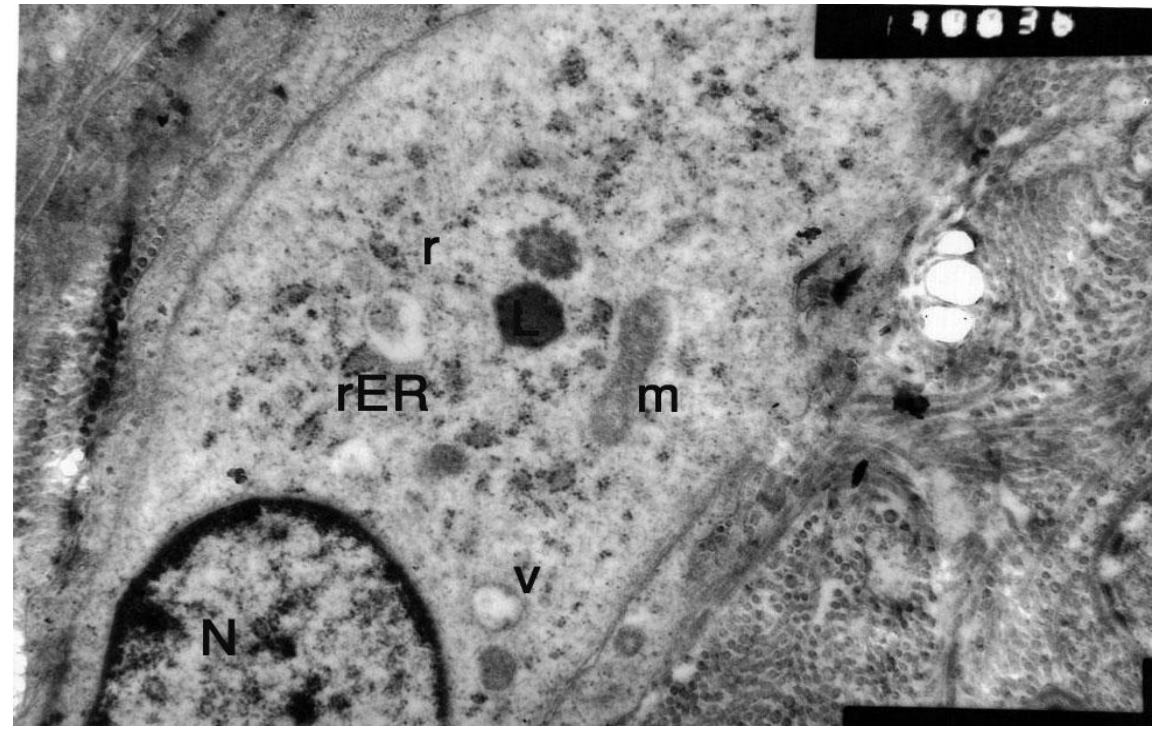

Fig (15): Transmission electron micrograph of Langerhans cell in the epidermis of young camel, showing part of the nucleus $(\mathrm{N})$, light cytoplasm containing lysosomes $(\mathrm{L})$, rough endoplasmic reticulum (rER), free ribosomes $(r)$, mitochondria $(m)$ and some membranous vesicles (v). (Mic. Mag. X 13000).

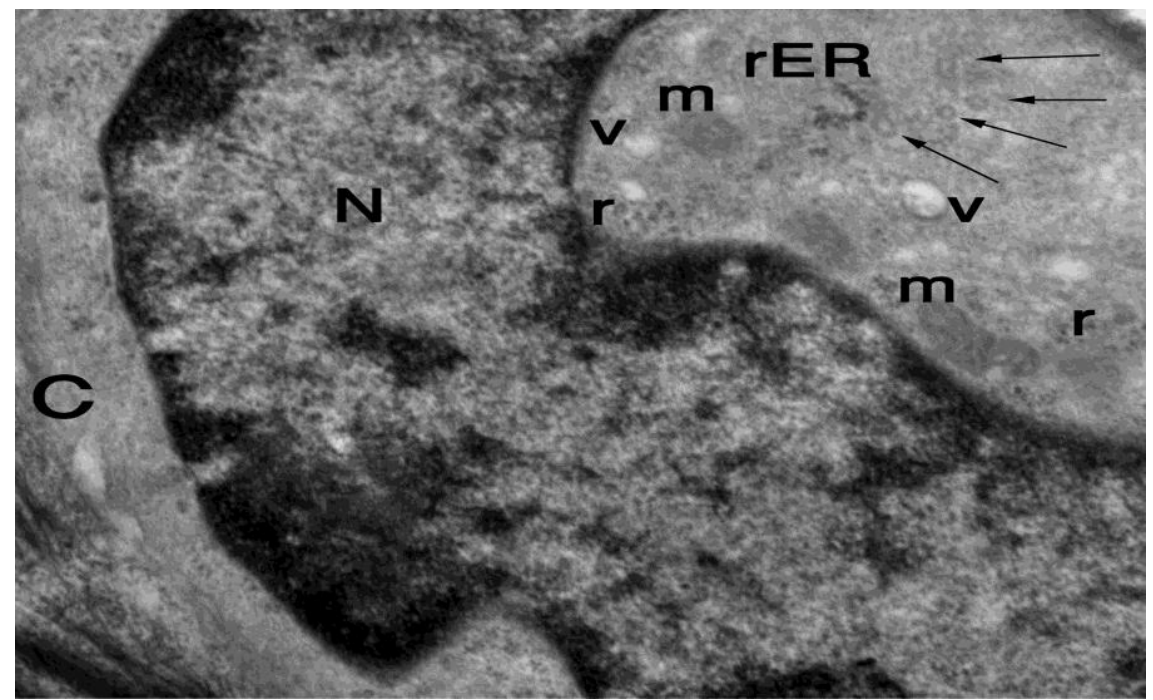

Fig (16): Transmission electron micrograph showing Langerhans cell in young camel basal epidermis, having electron lucent cytoplasm (C) containing specific Langerhans cell granules (arrows) in a transverse section with a limiting trilaminar unit membrane. The nucleus $(\mathrm{N})$ is nearly kidney-shaped. Mitochondria $(\mathrm{m})$, rough endoplasmic reticulum ( $r E R$ ), free ribosomes $(r)$ and some vesicles $(v)$ could be noticed in the cytoplasm. (Mic. Mag. X 10000). 


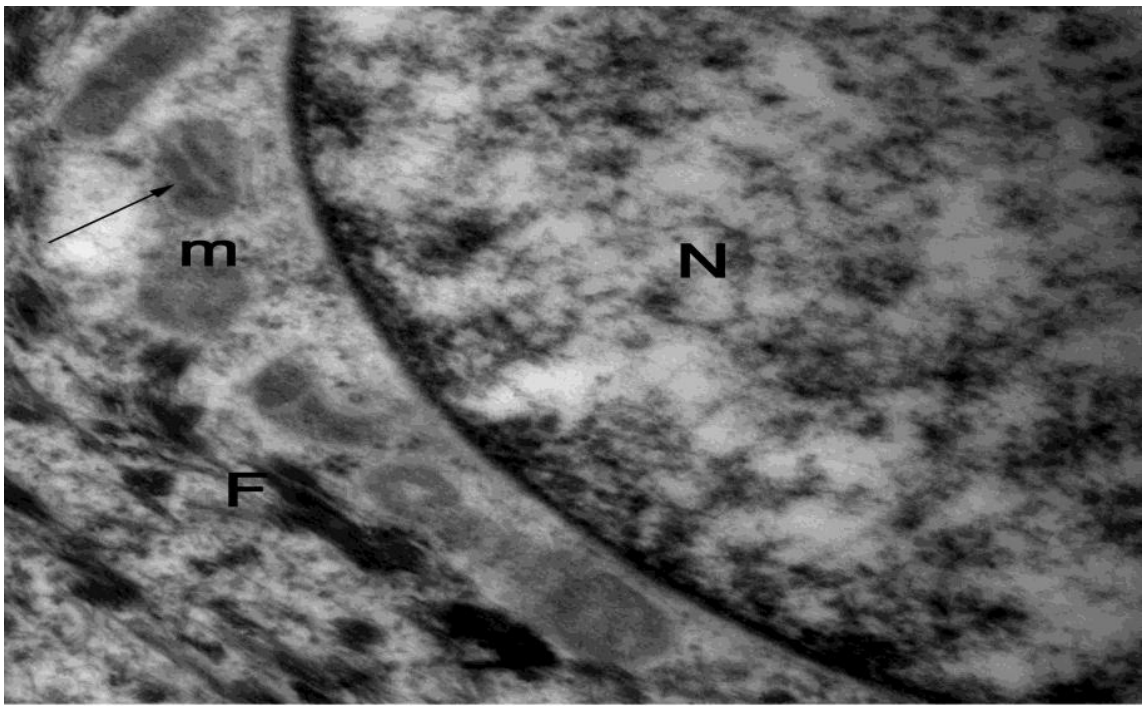

Fig (17): Transmission electron micrograph of Langerhans cell in young camel epidermis, showing an oblique section in its specific granules (arrow), mitochondria $(\mathrm{m})$, part of the nucleus $(\mathrm{N})$, and cytoplasmic filaments $(\mathrm{F})$ from the neighboring cell. (Mic. Mag. $X$ 13000).

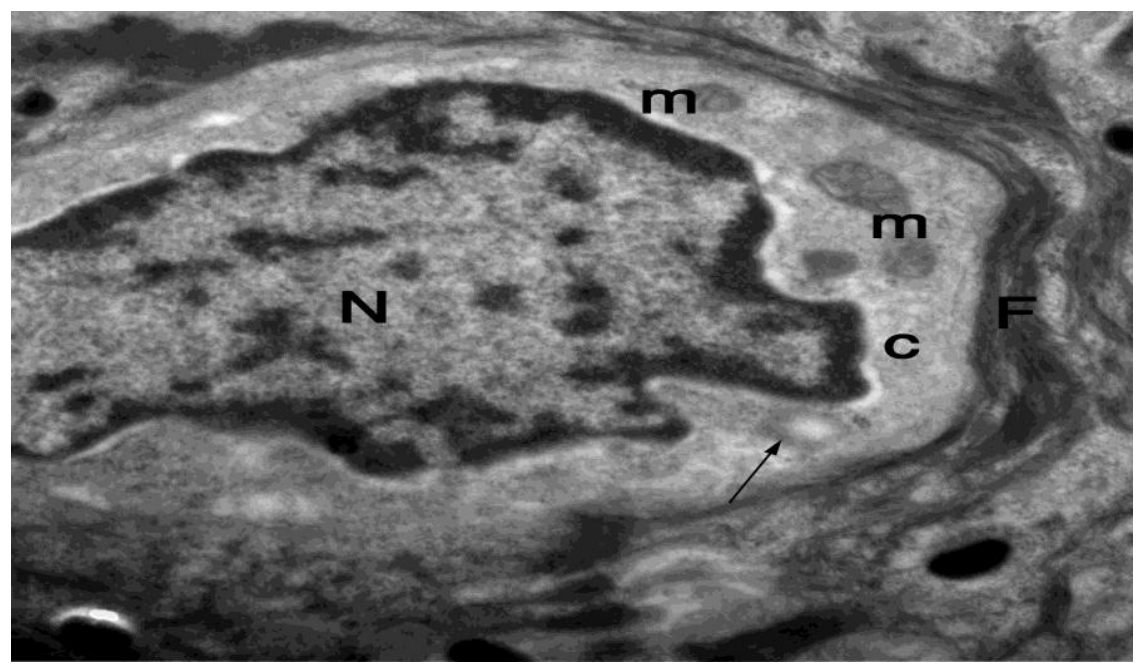

Fig (18): Transmission electron micrograph of the adult camel epidermis denoting, the electron lucent cytoplasm (c), cross section in the specific Langerhans cell granules (arrow), mitochondria $(\mathrm{m})$, nucleus $(\mathrm{N})$ and filaments $(\mathrm{F})$ from the neighboring cell. (Mic. Mag. X 7500). 


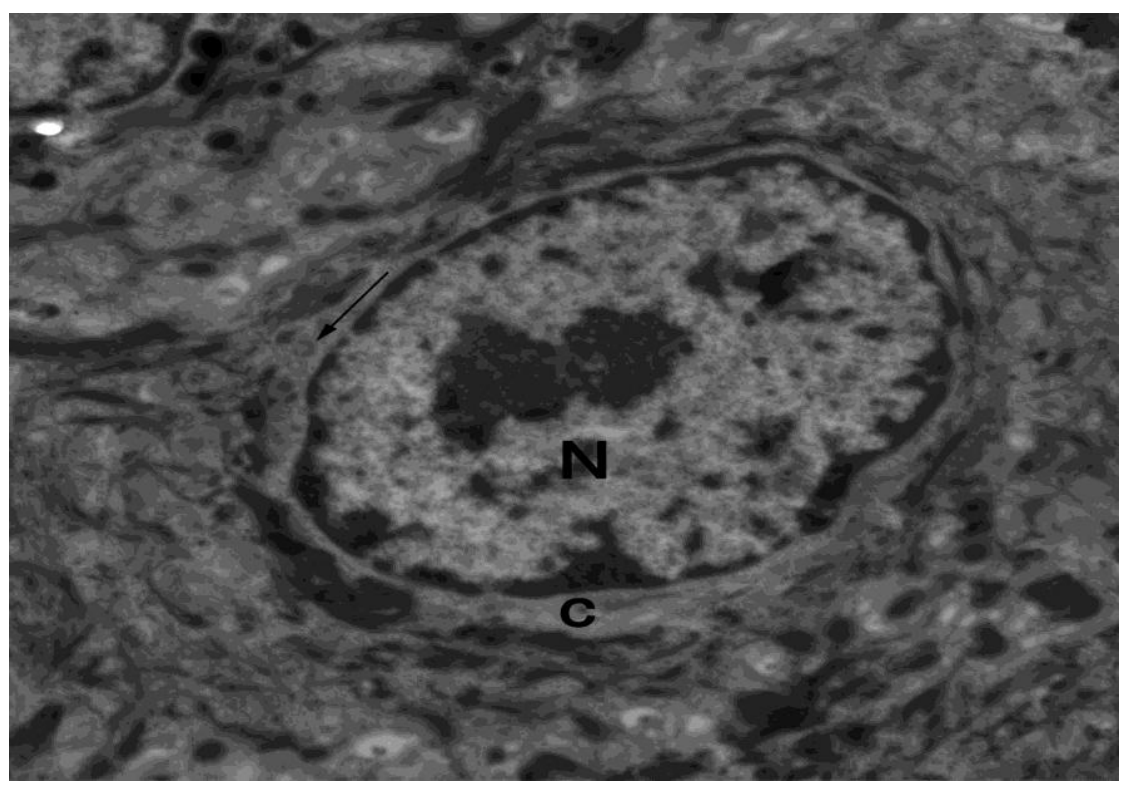

Fig (19): Transmission electron micrograph of Langerhans cell of adult camel epidermis showing, the cell with light cytoplasm (c), round to oval nucleus (N) and one specific granule (arrow). (Mic. Mag. X 5000) 